Penalized or Privileged? Sexual Identity, Gender, and Postsecondary Educational Attainment Author(s): Leigh E. Fine

Source: American Journal of Education, Vol. 121, No. 2 (February 2015), pp. 271-297

Published by: University of Chicago Press

Stable URL: http://www.jstor.org/stable/10.1086/679393

Accessed: 07-01-2016 18:25 UTC

Your use of the JSTOR archive indicates your acceptance of the Terms \& Conditions of Use, available at http://www.jstor.org/page/ info/about/policies/terms.jsp

JSTOR is a not-for-profit service that helps scholars, researchers, and students discover, use, and build upon a wide range of content in a trusted digital archive. We use information technology and tools to increase productivity and facilitate new forms of scholarship. For more information about JSTOR, please contact support@jstor.org. 


\title{
Penalized or Privileged? Sexual Identity, Gender, and Postsecondary Educational Attainment
}

\author{
LEIGH E. FINE \\ Kansas State University
}

\begin{abstract}
Prior literature on educational attainment indicates that there is both a female advantage and an LGB bonus: women are more likely to have earned bachelor's degrees than men, and lesbian, gay, and bisexual (LGB) persons are more likely to have earned a bachelor's degree than heterosexuals. Using data from the National Longitudinal Survey of Adolescent Health, I run logistic regressions on respondents' likelihood of having a bachelor's degree as a function of both gender and sexuality. I find that the female advantage and LGB bonus do not hold for sexual minority women, who are the gender and sexuality group least likely to have completed college.
\end{abstract}

\section{Introduction}

Educational attainment, or the ultimate level of education one achieves in his or her lifetime, affects life chances (Pascarella and Terenzini 2005), including future earnings (Bobbitt-Zeher 2007), health (Goesling 2007; Masters et al. 2012), and political engagement (Milligan et al. 2004). Because education can be such an important predictor of life chances, it is important to determine whether or not lesbian, gay, and bisexual (LGB) students are systematically privileged or disadvantaged with regard to educational attainment. ${ }^{1}$ The few studies that have attempted to analyze the relationship between educational attainment and sexual identity have indicated that gay men, on average, appear to have higher levels of education than do heterosexual men (Barrett et al. 2002; Black et al. 2000). ${ }^{2}$ 
However, there is a tension in the existing literature on educational attainment regarding lesbian and bisexual women's status. Some suggest that lesbian and bisexual women are also more likely to have bachelor's degrees as compared to heterosexuals (Black et al. 2000; Rothblum et al. 2005), but these works' methodological limitations make this conclusion problematic. Literature that specifically investigates lesbian and bisexual women's status attainment indicates that they may actually be educationally disadvantaged as compared to heterosexuals (Badgett 2001; Boatwright et al. 1996; Carpenter 2009). Because of this tension, it is important to determine which narrative - that of educational advantage or educational disadvantage - is most correct when applied to sexual minority women.

Here, I compare the educational attainment of four gender and sexuality groups - heterosexual men, heterosexual women, sexual minority men, and sexual minority women - to one another. I argue that the relationship between sexual identity and educational attainment is conditional on both sexuality and gender. To determine whether the "female advantage" (Buchmann and DiPrete 2006) in educational attainment holds for sexual minorities, I use the National Longitudinal Survey of Adolescent Health (Add Health) to estimate the influence of sexuality and gender on the probability of earning a bachelor's degree. I find that gay and bisexual men's educational attainment patterns more closely mirror heterosexual women's than heterosexual men's, meaning that sexual minority men do, in fact, enjoy a bonus with regard to educational attainment. Lesbian and bisexual women, on the other hand, have educational patterns that more closely parallel heterosexual men's, and further, they are the gender and sexuality group with the lowest predicted probability of having a bachelor's degree. The data indicate that the female advantage in college completion is inverted for sexual minorities, with sexual minority men more likely to have a bachelor's degree than sexual minority women. The interaction of gender and sexuality determines how LGB people fare educationally as compared to heterosexuals. Neither the female advantage nor LGB bonus literature, then, is sufficient to explain the current educational terrain for sexual minority women.

LEIGH E. Fine is an assistant professor in the Staley School of Leadership Studies at Kansas State University. 
What Is Known: The Female Advantage and the LGB Bonus

\section{The Female Advantage}

In the last few decades, women have obtained the majority of bachelor's degrees conferred in America (Buchmann and DiPrete 2006; Buchmann et al. 2008; DiPrete and Buchmann 2012). The female advantage in America started emerging in the 1980s, as males and females reached parity in bachelor's degree attainment. Since then, women have been outpacing men's college completion rates to the point where there are nearly two female college graduates for every one male college graduate today. DiPrete and Buchmann (2012) identify a number of reasons why this gender switch in educational advantage has taken place. The postindustrial transition of the American economy from manufacturing to service pushed women into the workforce, causing them to pursue higher education to receive better wages. Social beliefs regarding gender equity opened up educational institutions to women. Now that these institutions are open to them, women's superior academic performance and proschool behaviors mean they are more likely to succeed academically once they are in college as compared to men. Meanwhile, men and boys in some contexts interpret academic success - and the jobs associated with a college degree - as feminine (Legewie and DiPrete 2012; Morris 2008). Consequently, men's college completion rates have continued to lag behind those of women.

Although women are generally advantaged in terms of college completion as compared to men, the extent of the advantage varies by race and socioeconomic status. Black women have long outpaced black men educationally (DiPrete and Buchmann 2012; McDaniel et al. 2011). McDaniel et al. (2011) argue this is because of black women's longer relative involvement in the labor force, which provides a greater incentive to pursue higher education to obtain higher wages. Class also moderates gender's effect on educational attainment: the female advantage is less pronounced among wealthier Americans (Buchmann and DiPrete 2006; DiPrete and Buchmann 2012). Legewie and DiPrete (2012) argue this is because the upper class in America constructs a narrative of masculinity that values education as a means of competition, thus encouraging young men to pursue a bachelor's degree to prove one's worth relative to other men.

If the female advantage is not uniform but is moderated by race and class, sexuality may likewise moderate lesbian and bisexual women's educational attainment. The intersection of gender and sexuality may lead to distinctive educational outcomes for lesbian and bisexual women that differ from those of 
both heterosexual women and sexual minority men (Collins 2004). But little has been done to investigate how sexual minority women are faring educationally; studies that claim to examine the phenomenon either generalize findings on sexual minority men to women or study subgroups of women that are much more likely to be well educated.

\section{The LGB Bonus}

Because education is the social institution by which many in American society attempt to improve their wage prospects and life chances, it is important to determine how sexual identity affects one's likelihood of completing college. What little quantitative work has been done on the effect sexuality exerts on educational attainment indicates that LGB persons are actually advantaged educationally as compared to heterosexuals. I refer to this phenomenon as the "LGB bonus," akin to the female advantage in college completion. There are three known prior quantitative studies that explicitly focus on sexual identity and educational attainment. Black et al. (2000), Barrett et al. (2002), and Rothblum et al. (2005) all generally indicate that LGB people tend to have higher education levels than their heterosexual peers. However, all of these studies have methodological limitations that hinder their ability to lay a definitive claim to the relationship between sexual identity and educational attainment. I discuss the findings of these studies first and then explain how this work addresses their limitations.

Black et al. (2000) use 2000 US Census data and code anyone who indicates being partnered to someone of the same sex as gay or lesbian. The authors then compare several status attainment outcomes, such as income and education level, against partnered heterosexual persons, including measures of status attainment. Black et al. find that partnered gay men tend to have higher levels of education than do partnered heterosexual men. The authors state that there were not enough lesbians identified using this sampling method to make a strong comparison between partnered lesbians and partnered heterosexual women, so no tests were run for sexual minority women.

Barrett et al. (2002) use the Urban Men's Health Study to create a sample of 2,290 self-identified gay and bisexual males ${ }^{3}$ in the cities of San Francisco, Chicago, New York, and Los Angeles. They then run logistic regression analyses to determine how sexual identity influences status attainment, including educational attainment. They find that age of coming out is an important predictor of how much education the respondents had. Those who came out at earlier ages often had lower incomes and less education than heterosexual men; respondents who came out later in life tended to have higher incomes and education levels than heterosexual men. Barrett et al. hypothesize that, if 
someone comes out before college, family stress, discrimination, violence, or any number of negative sanctions for identifying as gay could prevent young out men from completing college. Males who came out after college, on the other hand, may have completed their educational attainment with few sexually related social sanctions and, thus, were able to focus on their education.

Rothblum et al. (2005) examine the relationship between sexuality and educational attainment using a sibling study. The researchers obtained copies of all civil union certificates from July 1, 2000, to June 30, 2001-the first year same-sex marriages were made legal in the state of Vermont. They then contacted these couples and asked them to identify heterosexual, married siblings to provide a comparison group. Out of their 335 LGB respondents, all were partnered and most were from the Northeast. The authors find that both lesbian women and gay men generally have higher levels of education than do their heterosexual siblings, though this does not translate to more economic gains for the sexual minority sibling. Rothblum et al. also note that causal order is difficult to determine; that is, do LGB people finish college and then come out, or do LGB people come out before completing a bachelor's degree?

All three studies document that LGB Americans tend to have higher education levels than heterosexuals. However, though they provide an initial glimpse into the influence of sexuality on educational attainment, important subgroups of LGB persons that may possibly have lower levels of education are excluded from their sample designs. Barrett et al. (2002) and Rothblum et al. (2005) focus on sexual minority persons who live in particular social contextsurban contexts and the Northeast, respectively. Thus their findings may not be nationally representative. Urbanites tend to be better educated as compared to those from rural contexts (Roscigno and Crowley 2001), and those from the Northeast tend to have higher levels of education than Americans from other regions (US Census Bureau 2012). Because they obtained respondents from contexts where all people are generally better educated, their findings may overestimate the education level of sexual minorities. ${ }^{4}$ Both Black et al. (2000) and Rothblum et al. (2005) study only partnered respondents. Those LGB persons who tend to report being monogamously coupled are also more likely to have higher levels of education, as they are largely white and affluent (Polikoff 2008; Taylor et al. 2009). Therefore, because these two studies look at partnered respondents and exclude single LGB people, the calculated levels of educational attainment for sexual minorities may be artificially inflated.

More problematic, though, is the exclusion of female respondents. Neither Black et al. (2000) nor Barrett et al. (2002) examined lesbian and bisexual women's educational attainment. Although both study designs have strong rationales for doing so, excluding women from these analyses is a concern because it provides an incomplete picture of the educational status of all LGB persons. The intersection of social identities can lead to unique, nonadditive 
outcomes for social groups (Collins 2004). The female advantage, then, may be moderated by sexuality and the LGB bonus by gender. Gay and bisexual men may be more likely to obtain a bachelor's degree than their heterosexual counterparts, whereas lesbian and bisexual women are less likely. As of now, it is ultimately unknown how heterosexual men, heterosexual women, sexual minority men, and sexual minority women stand relative to one another in terms of educational attainment. There is reason to believe that prior research has been remiss in generalizing both the LGB bonus and the female advantage to sexual minority women. Sexuality, like race and class, would need to be taken into account in studying the female advantage if lesbian and bisexual women's likelihood of earning a bachelor's degree is below that of heterosexual women's. Likewise, the LGB bonus literature would have to exert care in generalizing findings about the educational attainment of LGB people generally to sexual minority women.

\section{Method}

\section{Hypotheses}

I argue that educational attainment is contingent on both sexuality and gender. Prior work provides reason to believe that the female advantage may not hold for LGB people. I conduct an analysis that compares the predicted likelihood of having a college degree for four gender and sexuality groups: sexual minority women, sexual minority men, heterosexual women, and heterosexual men. Informed by the literature, I propose the following hypotheses:

HYPOTHESIS 1.- Heterosexual women will be more likely to earn a bachelor's degree than heterosexual men.

HYPOTHESIS 2.- Sexual minority men will be more likely to earn a bachelor's degree than heterosexual men.

HYPOTHESIS 3.- Sexual minority women's likelihood of earning a bachelor's degree differs from that of heterosexual women's, but it is unknown what direction the effect will take.

HYPOTHESIS 4.- Sexual minority women's likelihood of earning a bachelor's degree differs from that of sexual minority men's, but it is unknown what direction the effect will take.

The first two hypotheses are largely supported by prior literature on the female advantage and the LGB bonus. Hypothesis 2 is further supported by the literature that outlines the differences between sexual minority men's and 
women's likelihood of completing college, as discussed above. Hypotheses 3 and 4, though, claim that the female advantage and LGB bonus may not hold for sexual minority women, leading to markedly different educational outcomes for them as compared to heterosexual women or sexual minority men.

\section{Data}

I use data from the National Longitudinal Study of Adolescent Health (Add Health; Harris et al. 2009). These data are an improvement over prior studies for several reasons. Add Health data are nationally representative; respondents come from a variety of geographic contexts, not just from urban areas. Add Health did not oversample for LGB respondents as it did for other groups, such as racial minorities. However, as respondents were first identified at a young age, before a full articulation of their sexual identities would be likely (Cass 1979; Savin-Williams 2005), the fact that the data are nationally representative otherwise should allay concerns of selection bias issues within the LGB population identified here. ${ }^{5}$ The data contain a sufficient number of cases for both sexual minority men and women to investigate potential gender and sexuality differences in educational attainment. Add Health also includes multiple questions that can be used to classify respondents as sexual minorities, an important consideration given my hypotheses.

Four waves of Add Health data have been collected to date. I use the publicly available first and fourth waves of Add Health in this study. ${ }^{6}$ Wave 1 data were collected in 1994-95, when respondents were in grades 7-12. This wave provides background characteristics about respondents, which served as control variables. For example, information about respondents' family lives, early educational careers, and basic demographic characteristics, such as race, age, and gender, are included in analyses because of their effect on educational attainment. The most recent wave, wave 4, was collected in 2007-8, when respondents' average age was almost 30 years - past the age when the majority of Americans complete their college degrees (Jacobs and King 2002). Wave 4 provides both the dependent variable, educational attainment, and the independent variable, self-reported sexual identity. The final sample size is 4,984 respondents after merging data and dealing with missing cases, which I describe in more detail below.

\section{Independent Variable: Sexual Identity}

I use self-identification of sexual identity at the time of wave 4 as my independent variable. At wave 4, respondents were asked, "Which of these choices 
best describes you?" Akin to Kinsey et al.'s (1948) scale, respondents were allowed to place their sexual identity somewhere along a 1-5 scale. Add Health's scale asked respondents to rate themselves from 1 to 5 on the sexual identity question, with a rating of 1 being " 100 percent heterosexual," a rating of 3 being bisexual, and a rating of 5 being "100 percent homosexual (gay)" (Harris et al. 2009). Those who answered 3, 4, or 5 on this question were coded as LGB. ${ }^{7}$ Fifty-five respondents indicated they felt no sexual attraction, commonly referred to as asexual (Boegart 2006); these cases were dropped from the analysis. ${ }^{8}$

Admittedly, any attempt to operationalize sexual identity is not without its problems. Despite the limitations of the data, no method of measuring sexual identity is generally accepted (Savin-Williams 2005). Depending on how sexual identity is measured-based on sexual behavior, romantic attraction, physical attraction, dating behavior, or self-identification - respondents may give very different answers (Laumann et al. 1994; Savin-Williams 2005). Despite these issues, I maintain that self-identification is the preferable measure for this work. Use of wave 4 self-identification to measure LGB status mitigates issues of construct validity that wave 1 measures present and also captures some of the potential effects of social sanctioning in ways that behavioral or attraction measures do not. If respondents disclose sexual minority identification in Add Health, it is likely that they have also disclosed sexual minority status in other settings and thus may have experienced some of the negative social forces others impose on those who are sexual minorities through other social disclosure (Fine 2011; Pharr 1997). Even if they are not publicly out, acknowledging their own sexual identity as a minority may make them more acutely aware of prejudice and discrimination (Cass 1979), which could alter their social experience and self-concept. Also, self-identification is one of the most conservative measures, with fewer respondents reporting a selfidentification as a sexual minority than engaging in same-sex sexual behavior or other operationalizations (Laumann et al. 1994). If persons identify as LGB by wave 4 , regardless of whether or not they did so at or before wave 1 data collection, their educational trajectories still contribute to a general pattern of self-identified LGB persons' relative educational standing as compared to heterosexuals. Similarly, even if education led to the development or disclosure of a sexual minority identity, the fact that respondents now identify as LGB means that their educational attainment level still speaks to a larger demographic pattern that illustrates the relationship between sexuality and education. Table 1 shows the sexual identity and gender breakdown of the sample. Of 4,984 respondents, 183 (3.67\% of the sample) identified as lesbian, gay, or bisexual. ${ }^{9}$

It is important to acknowledge that endogeneity may also be present in using a wave 4 measure as compared to other means of operationalizing sexual 
TABLE 1

Gender and Sexual Identity of Sample

\begin{tabular}{lcrr}
\hline & Female & Male & Total \\
\hline Heterosexual & 2,223 & 2,578 & 4,801 \\
Lesbian, gay, or bisexual (LGB) & 70 & $\frac{113}{2,691}$ & $\frac{183}{4,984}$ \\
\cline { 2 - 4 } & $\mathbf{N}$ & 2,293 & \\
\hline
\end{tabular}

identity that come from earlier waves. It is possible that higher levels of education may lead to a higher likelihood of respondents identifying as LGB, either because education has exposed them to alternate social possibilities or because of contact with successful, educated role models that can provide social support (Rhoads 1995). Although sexual minorities are coming out at earlier ages, many of them before they enter college (Broido 2004; SavinWilliams 2005), it is still possible that the causal order may be reversed for some respondents. A key limitation of the Add Health data as they stand is the absence of a variable that reports when LGB respondents came out - that is, first publicly disclosed their sexual identities. This is important because, although one may acknowledge oneself as being LGB, the development of a public identity can translate to discrimination from others (Cass 1979). A gay man who came out after college likely had a radically different experience than a gay man who has been out since adolescence. The respondent who came out later in life may not have experienced the same forces of discrimination and prejudice as the latter student — or, at least, he may not have experienced them in the same manner (Barrett et al. 2002; Henrickson 2008). Further, coming out is not a standard process, and sexual minority people can vary in their conceptualizations as to what makes one LGB or not (SavinWilliams 2005). Because it is not possible to know at what point in their lives the LGB respondents came out, or if they are out publicly, these data cannot answer the question of how the timing of coming out affects educational outcomes. Future work with more comprehensive data may examine how the timing of coming out may affect educational attainment.

\section{Dependent Variable and Analysis}

Add Health asks respondents at each wave about their highest level of education attained. The wave 4 question on highest degree earned was used to construct the dependent variable. Respondents who reported having earned a bachelor's degree or higher by the time of wave 4 data collection were coded as 1 ; those with less education were coded as 0 . Table 2 shows the highest 
TABLE 2

College Graduation Status and Sexual Identity of Sample

\begin{tabular}{|c|c|c|c|}
\hline Education Level & Less than Bachelor's & Bachelor's or Higher & Total \\
\hline Heterosexual & 3,208 & 1,593 & 4,801 \\
\hline Lesbian, gay, or bisexual (LGB) & 129 & 54 & 183 \\
\hline Total & 3,337 & 1,647 & $\overline{4,984}$ \\
\hline
\end{tabular}

education level achieved as reported by respondents. By the time of wave 4 data collection, 33.05\% of all respondents and 29.51\% of LGB respondents had earned a bachelor's degree. ${ }^{10}$ Because the variable is dichotomous - respondents either have attained a bachelor's degree or they have not - I use logistic regression techniques to analyze the relationship between sexual identity and educational attainment (Pampel 2000). Data were weighted using Add Health-provided weights (Harris et al. 2009). I estimate two models: one including an interaction term for gender and LGB self-identified sexuality and one without. Because hypotheses 3 and 4 do not specify a direction for the effects of sexuality on educational attainment, and to ensure a more stringent threshold for significance given the relatively small sample size of LGB respondents as compared to heterosexuals, I employ two-tailed tests for all variables. I use results from the second logistic regression model, which includes the interaction term, to predict the probability of having a bachelor's degree as a function of gender and sexual identity in order to compare all four gender and sexuality groups - heterosexual men, heterosexual women, sexual minority men, and sexual minority women - to one another directly.

\section{Control Variables}

All other variables come from wave 1 of data collection and are treated as controls, as they capture background characteristics that prior literature indicates are correlated with educational attainment. Although half of all Add Health respondents are aged 29-31 by the time of wave 4 data collection, the range of ages spans 10 years. Respondent age is included as a control to compensate for its effects on educational attainment, as older respondents may have had more time to obtain higher education.

Parent characteristics, like education and occupation, are important in determining status attainment, including educational attainment (Bobbitt-Zeher 2007; Buchmann and DiPrete 2006; Sewell et al. 1969). This work uses Bearman and Moody's (2004) method of measuring the relative social class of Add 
Health wave 1 respondents' families, combining the occupational prestige and the education level of their parents. Their method is quite useful, as it provides a comprehensive socioeconomic status (SES) measure with a minimum of missing cases. Wave 1 of the Add Health survey asks its respondents to report on their parents' education levels and occupation. ${ }^{11}$ Bearman and Moody developed a scheme for measuring both occupational prestige and educational attainment for each parent and then adding the values together to provide an SES measure based on the status of each individual parent on a 1-10 scale. Should data be available for both a father and a mother, the larger of the two values is used to measure family SES. SES values were not calculated for parents who were missing values on either occupation or education level. I describe how I deal with missing data for family SES below.

Attitudes, desires, and drives are also important predictors of an individual's likelihood of attaining higher education (Sewell et al. 1969). In wave 1, before respondents were of age to begin college, respondents were asked how likely they thought it would be that they would go to college. This question was asked using a Likert scale from 1 to 5 , with 5 corresponding to a higher perceived likelihood of the respondent's chances of going to college. This question may capture both respondents' aspirations as well as any practicalities that may affect their perceived likelihood of obtaining higher education.

Respondents' self-esteem was also measured using a battery of questions in Add Health's first wave. Self-esteem can be an important force in determining how far one may pursue higher education (Chickering and Reisser 1993; Sewell et al. 1969). Particularly for LGB students, who may suffer from lower self-esteem than their heterosexual peers generally (D’Augelli 1993), selfesteem may be an important predictor of further educational attainment. ${ }^{12} \mathrm{I}$ use the same method as Longmore et al. (2004) to measure self-esteem. A battery of six questions within Add Health is used to construct the self-esteem variable: "I have a lot of good qualities," "I have a lot to be proud of," "I like myself just the way I am," "I feel like I'm doing everything just about right," "I feel socially accepted," and "I feel loved and wanted." These questions measure perceived self-efficacy and social connectedness, both components of self-esteem that may affect educational attainment. Each question is answered on a scale from 1 to 5, with higher values indicating higher self-esteem. I then use the total of these six items to measure self-esteem in my models. Respondents were included if they provided answers to at least four of the six items; those with missing values had the total value for the responses they did answer scaled to match those who answered all six items.

Students who enjoy greater academic success earlier in their educational careers may be more likely to gain admission into college or be encouraged by significant others to obtain a bachelor's degree (Sewell et al. 1969). I use McNeely's (2005) method to operationalize grade point average (GPA), as it min- 
imizes the number of missing cases using the available data. Students provide self-reported grades in four core subjects in the Add Health data set at wave 1: math, English, science, and social studies/history. Converting letter grades to numeric values $(\mathrm{A}=4, \mathrm{~F}=0)$, the average of students' self-reported grades in these four subjects is used to measure prior academic performance. Also following McNeely's method, students were included in the sample if they reported grades in at least two of four subjects. Treatment of missing data for cumulative GPA at wave 1 is described below. ${ }^{13}$

Race is included as a control variable in this study, as there continue to be racial gaps in education (Chapa and de la Rosa 2004; Goldsmith 2009; McDaniel et al. 2011). Race was coded from wave 1 data, when respondents indicated their racial backgrounds. Those who indicated more than one racial background or who indicated a race other than white, black, Latino/a, or Asian were coded as being from another race to avoid the loss of LGB respondents. ${ }^{14}$ Those who did not provide data on their race were dropped from the analysis. The analysis contains five racial groups: white, black, Latino/a, Asian, and other, with white respondents acting as the reference group.

Geographic context is included as a control variable as well, as it can have an effect on one's likelihood of pursuing higher education. Those from urban contexts may be less likely to attend well-funded schools (Kozol 1991; Ryan 2010), which leaves them disadvantaged in the pursuit of higher education. Likewise, rural schools may be underfunded, and student culture may disdain the pursuit of higher education in favor of blue-collar careers (Morris 2008). Wave 1 interviewers coded the respondent's residence at the time of the interview as living in an urban, rural, suburban, or a different locale (e.g., a predominantly industrial area). Respondents whose interviewer did not provide a code for their urban context were coded as living in another locale. Suburban residents were used as the reference group.

\section{Missing Data}

I merge control variable data from wave 1 with independent and dependent variable data from wave 4 for all respondents. For the independent variable, all respondents who did not report a sexual identity, or who identified as asexual, are not included in the analysis. For the dependent variable, one respondent who did not provide information on highest degree attained is excluded from the sample. For most other control variables, I choose to use listwise deletion to deal with missing cases, as this method preserved over $98 \%$ of respondents who provided data for both wave 1 and wave 4 of Add Health (Allison 2001). Listwise deletion led to a loss of five LGB respondents out of an initial 188 , or $2.66 \%$ of the total LGB sample. 
After listwise deletion of cases for missing values on all other variables, 407 respondents, or $8.17 \%$ of the sample, have missing data on family SES, GPA, or both. This number includes 19 LGB respondents, or $10.38 \%$ of the remaining LGB sample. Because the number of sexual minority respondents is relatively small as compared to the total sample size, listwise deletion would have eliminated a large number of cases, lowering the statistical power of the analysis. To preserve these cases, I code those with missing cases for SES or GPA as 0 and then include a dummy variable for missing values on these variables in the models. Although the use of dummies as proxies for missing data may lead to biased estimators, it may be a useful way of preserving statistical power given a small sample size (Allison 2001).

I test the appropriateness of using dummies as proxies for missing data by running comparison models that use listwise deletion of all cases with missing variables and multiple imputation techniques (results not shown). Results from data that used multiple imputation and listwise deletion of all missing cases were similar to those from the model that used dummy variables to code for missing data. Coefficients for the dummy variable models used here also provide the most conservative estimates of the three methods tested for dealing with missing data. Table 3 shows the weighted means, standard deviations, and range of all variables used in the final analysis.

Results

Table 4 shows the results of the regression analysis. Model 1 runs the analysis without an interaction term for gender and LGB sexuality. The coefficient for sexual minority status is not significant in this model.

Model 2 adds the interaction term to the analysis. The effect of sexual identity on bachelor's degree completion by the time of wave 4 data collection is positive and statistically significant with the addition of the interaction term to the analysis. ${ }^{15}$ This indicates that sexuality does exert an effect on educational attainment, but only when an interaction with gender is added to the model. That is, the effect of sexual identity on educational attainment is positive for men but negative for women. The main effect for gender is also significant, in keeping with prior literature. Women in the Add Health data set demonstrate the female advantage in college completion is still present, as they are more likely than heterosexual men to have a bachelor's degree, controlling for all other variables $(b=0.3980, p<.001)$.

The interaction effect in model 2 for gender and sexual identity is also significant. The significance of both the main term and interaction term in model 2 indicates that there is a significant difference between the educational attainment patterns of sexual minority women and men. Unlike the main ef- 
TABLE 3

Descriptive Statistics of Sample

\begin{tabular}{|c|c|c|c|c|}
\hline & Mean & SE & Range Low & Range High \\
\hline College graduate & .31 & & 0 & 1 \\
\hline Lesbian, gay, or bisexual (LGB) & .04 & & 0 & 1 \\
\hline Female & .50 & & 0 & 1 \\
\hline Female $\times$ LGB & .02 & & 0 & 1 \\
\hline \multicolumn{5}{|l|}{ Race: } \\
\hline Black & .15 & & 0 & 1 \\
\hline Latino & .11 & & 0 & 1 \\
\hline Asian & .02 & & 0 & 1 \\
\hline Other race & .04 & & 0 & 1 \\
\hline White & .68 & & 0 & 1 \\
\hline Age & 29.54 & .03 & 25 & 35 \\
\hline \multicolumn{5}{|l|}{ Urbanity: } \\
\hline Urban & .30 & & 0 & 1 \\
\hline Rural & .28 & & 0 & 1 \\
\hline Other locale/not reported & .04 & & 0 & 1 \\
\hline Suburban & .38 & & 0 & 1 \\
\hline Family SES ${ }^{a}$ & 5.38 & .05 & 0 & 10 \\
\hline Missing SES & .05 & & 0 & 1 \\
\hline Likely will go to college & 4.15 & .02 & 1 & 5 \\
\hline Self-esteem & 24.74 & .06 & 6 & 30 \\
\hline Cumulative wave $1 \mathrm{GPA}^{\mathrm{a}}$ & 2.30 & .01 & 0 & 4 \\
\hline Missing GPA & .04 & & 0 & 1 \\
\hline $\mathcal{N}$ & 4,984 & & & \\
\hline
\end{tabular}

a Weighted using Add Health-provided weights. Cases with missing data coded as 0 . Lower bound for cases with data is 1 .

fect for sexual identity, though, the interaction term is negative, indicating that the relationship between sexuality and educational attainment is conditional on gender. Whereas gay and bisexual men are more likely than heterosexual men to have earned a bachelor's degree by wave 4, lesbian and bisexual women are less likely as compared to heterosexual men, net of other effects (interaction effect $b=-1.6149, p<.001$; summation of main effects and interaction effects $=-0.2158)$. Sexual minority men, then, enjoy an educational bonus compared to heterosexuals - men and women. Sexual minority women, on the other hand, suffer a penalty in terms of their educational attainment.

The direction and significance of the control variables' effects in model 2 are largely in keeping with prior literature. Asian respondents were more likely to have a bachelor's degree by wave 4 than white respondents, while black respondents were less likely to have a bachelor's degree. Respondents who are older with higher SES and higher GPAs were also more likely to

\section{American Journal of Education}


TABLE 4

Logistic Regression of Variables on Likelihood of Having a Bachelor's Degree by Wave 4

\begin{tabular}{|c|c|c|c|c|c|c|}
\hline & \multicolumn{3}{|c|}{ MODEL 1} & \multicolumn{3}{|c|}{ MODEL 2} \\
\hline & $b$ & $\mathrm{SE}$ & $\begin{array}{l}\text { Odds } \\
\text { Ratio }\end{array}$ & $b$ & $\mathrm{SE}$ & $\begin{array}{l}\text { Odds } \\
\text { Ratio }\end{array}$ \\
\hline \multicolumn{7}{|l|}{ Lesbian, gay, or } \\
\hline bisexual (LGB) & .0821 & 2307 & .8562 & $1.0011 * *$ & .3282 & 2.1831 \\
\hline Female & $.3437 * * *$ & .0821 & 1.2433 & $.3980^{* * * *}$ & .0834 & 1.3154 \\
\hline Female $\times$ LGB & & & & $-1.6149 * * *$ & .4542 & .1933 \\
\hline \multicolumn{7}{|l|}{ Race: $^{\mathrm{a}}$} \\
\hline Black & $-.3481 *$ & .1111 & .7462 & $-.3534 * *$ & .1116 & .7422 \\
\hline Latino & -.1542 & .1492 & .7620 & -.1618 & .1497 & .7579 \\
\hline Asian & $.8216^{* *}$ & .2445 & 2.1009 & $.8297 * *$ & .2474 & 2.1243 \\
\hline Other race & -.1804 & .1914 & .7715 & -.1967 & .1929 & .7578 \\
\hline Age & $.0727 * *$ & .0213 & .8513 & .0721 ** & .0213 & .8509 \\
\hline \multicolumn{7}{|l|}{ Urbanity: ${ }^{b}$} \\
\hline Urban & $-.2542 *$ & .0987 & .7245 & $-.2585^{* *}$ & .0989 & .7205 \\
\hline Rural & -.0641 & .1011 & .8451 & -.0722 & .1013 & .8386 \\
\hline \multicolumn{7}{|l|}{ Other locale/not } \\
\hline reported & -.0930 & .2104 & .8859 & -.1263 & .2098 & .8555 \\
\hline Family SES & $.2925^{* * *}$ & .0167 & 1.3093 & $.2935^{* * * *}$ & .0168 & 1.3106 \\
\hline Missing SES & $.6905^{* *}$ & .2552 & 1.6997 & $.7063^{* *}$ & .2581 & 1.7368 \\
\hline \multicolumn{7}{|l|}{ Likely will go to } \\
\hline college & $.7786^{* * *}$ & .0577 & 1.9197 & .7737 **** & .0575 & 1.9131 \\
\hline Self-esteem & .0093 & .0116 & .9457 & .0089 & .0117 & .9457 \\
\hline \multicolumn{7}{|l|}{ Wave 1 cumulative } \\
\hline GPA & $.6512^{* * * *}$ & .0891 & 1.5127 & $.6512^{* * * *}$ & .0892 & 1.5122 \\
\hline Missing GPA & .4727 & .3499 & 1.1181 & .4669 & .3527 & 1.1184 \\
\hline Constant & $-9.9717 * * * *$ & .7977 & & $-9.9501 * * *$ & .8013 & \\
\hline Pseudo $R^{2}$ & .2357 & & & .2383 & & \\
\hline $\mathcal{N}$ & 4,984 & & & & & \\
\hline
\end{tabular}

${ }^{a}$ Reference group is white.

${ }^{b}$ Reference group is suburban.

$* p<.05$.

$* * p<.01$.

$* * * *<<.001$.

have a bachelor's degree. All these effects are statistically significant. Respondents who were coded as living in urban contexts were less likely than suburbanraised respondents to have a college degree, and the effects are statistically significant. Belief in wave 1 that one would eventually go to college was statistically significant and positively associated with bachelor's degree attainment; however, self-esteem was not.

In order to compare gender and sexuality groupings, ${ }^{16}$ I estimate margins and linear contrasts for all four gender and sexuality combinations. Table 5 
TABLE 5

Predicted Probability of Having a Bachelor's Degree and Significance of Contrasts

\begin{tabular}{|c|c|c|c|c|c|}
\hline Group & & $\mathrm{P}(\mathrm{r})$ & & & \\
\hline Heterosexual men & & .2779 & & & \\
\hline $\begin{array}{l}\text { Heterosexual } \\
\text { women }\end{array}$ & & .3403 & & & \\
\hline $\begin{array}{l}\text { Sexual minority } \\
\text { men }\end{array}$ & & .4414 & & & \\
\hline Sexual minority & & & & & \\
\hline Women & & .2462 & & & \\
\hline Reference Group & $\begin{array}{l}\text { Comparison } \\
\text { Group }\end{array}$ & Contrast & SE & $\begin{array}{c}|p|<z, \\
\text { Bonferroni- } \\
\text { adjusted }\end{array}$ & $\begin{array}{c}|p|<z, \\
\text { no } \\
\text { adjustment }\end{array}$ \\
\hline $\begin{array}{l}\text { Heterosexual } \\
\text { men }\end{array}$ & $\begin{array}{l}\text { Heterosexual } \\
\text { women }\end{array}$ & .0624 & .0130 & $* * *$ & $* * *$ \\
\hline $\begin{array}{l}\text { Heterosexual } \\
\text { men }\end{array}$ & $\begin{array}{l}\text { Sexual minority } \\
\text { men }\end{array}$ & .1635 & .0557 & $*$ & $* *$ \\
\hline $\begin{array}{l}\text { Heterosexual } \\
\text { men }\end{array}$ & $\begin{array}{l}\text { Sexual minority } \\
\text { women }\end{array}$ & -.0316 & .0452 & NS & NS \\
\hline $\begin{array}{l}\text { Heterosexual } \\
\text { women }\end{array}$ & $\begin{array}{l}\text { Sexual minority } \\
\text { men }\end{array}$ & .1011 & .0556 & NS & NS \\
\hline $\begin{array}{l}\text { Heterosexual } \\
\text { women }\end{array}$ & $\begin{array}{l}\text { Sexual minority } \\
\text { women }\end{array}$ & -.0941 & .0452 & NS & $*$ \\
\hline $\begin{array}{l}\text { Sexual minority } \\
\text { men }\end{array}$ & $\begin{array}{l}\text { Sexual minority } \\
\text { women }\end{array}$ & -.1951 & .0704 & * & $* *$ \\
\hline
\end{tabular}

shows the predicted probabilities of each group having a bachelor's degree by wave 4 . Gay and bisexual men have the highest predicted probability of having completed college at 0.4414 . They are followed by heterosexual women, whose predicted probability is 0.3403 . Heterosexual men's predicted probability of having a bachelor's degree by wave 4 is 0.2779 . Lesbian and bisexual women have the lowest predicted probability of all gender and sexuality groupings of finishing college at 0.2462 . These probabilities are represented graphically in figure 1 .

I run tests on the contrasts between these predicted probabilities to determine whether they differ from one another at a statistically significant level. I present results using both Bonferroni corrections and no postestimation adjustments. Although Bonferroni tests are generally the preferred method to lessen Type I error across multiple estimations - that is, lessening the likelihood

\section{American Journal of Education}




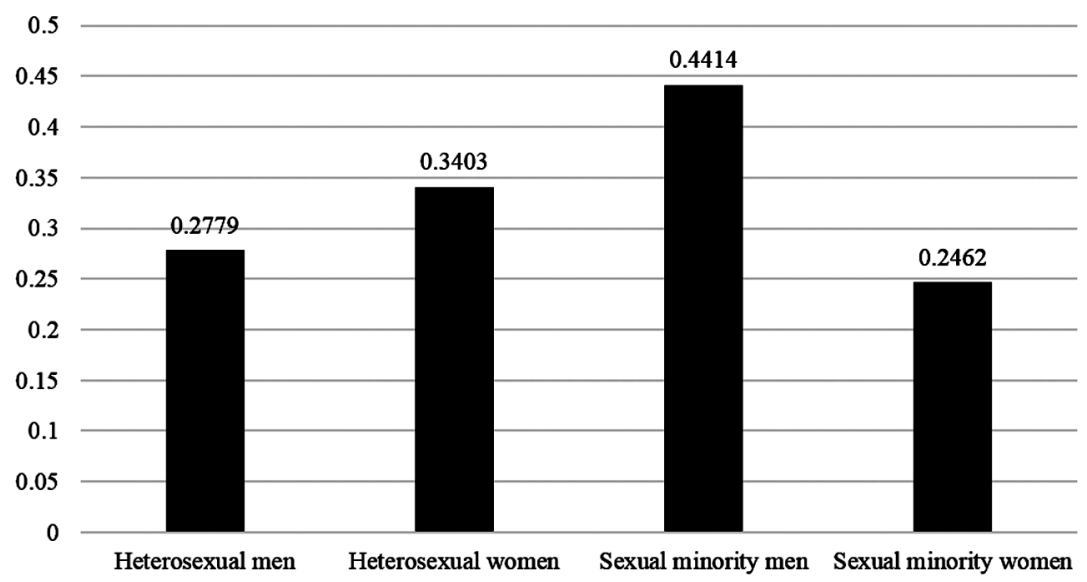

FIG. 1.-Predicted probability of having a bachelor's degree by wave 4

that a relationship will be deemed statistically significant based on chance (Brown 2008) - they also reduce statistical power (Perneger 1998). Because the sample size of LGB respondents is relatively small as compared to the number of heterosexual respondents, the Bonferroni correction may cause the null hypothesis - that the intersection of gender and sexuality does not have a statistically significant influence on educational attainment - to be upheld even if it should be rejected. Therefore, I present the results of both methods of calculating significance.

The contrast between heterosexual men's and heterosexual women's predicted probability is statistically significant regardless of whether the Bonferroni correction is employed $(p<.001)$, which indicates that the female advantage in educational attainment holds using these data when comparing heterosexual men to heterosexual women. Two contrasts were not significant regardless of whether the Bonferroni adjustment was employed: the contrast in predicted probabilities between sexual minority men and heterosexual women and the contrast between sexual minority women and heterosexual men. This is telling, as it indicates that LGB women's predicted probability of college completion likely mirrors that of heterosexual men more closely than it does that of heterosexual women. LGB men's pattern of attainment, on the other hand, is likely more closely related to that of heterosexual women instead of that of heterosexual men.

Sexual minority men's educational attainment is higher than that of heterosexual men, which is in keeping with prior findings from the literature. Gay 
and bisexual men's predicted probability of having completed a bachelor's degree is 16 percentage points higher than heterosexual men's, and this contrast is statistically significant regardless of whether the Bonferroni correction is applied. As compared to sexual minority women, sexual minority men's predicted probability of completing college is over 19 percentage points higher. Again, this difference holds as statistically significant both using no adjustment and using Bonferroni's adjustment.

The question of whether the contrast between sexual minority women and heterosexual women is significant depends on whether nonadjusted or Bonferroni-adjusted tests of significance are employed. Heterosexual women's predicted probability of having a bachelor's degree was over 9 percentage points above that of lesbian and bisexual women. This difference is statistically significant if no adjustment is used $(p<.05)$ and insignificant if the Bonferroni adjustment is used. Although the more conservative Bonferroni tests prevent the model from making an inaccurate rejection of the null hypothesis, the already-small sample size means that employing the Bonferroni correction may be incorrectly upholding the null hypothesis, given the strength of the findings from the logistic regression model. Future research with larger sample sizes of LGB respondents, or qualitative research that compares the educational narratives of LGB women to those of heterosexual women, may be able to validate these differences.

\section{Discussion}

The logistic regression model and unadjusted tests of predicted probabilities indicate that sexual identity has an effect on educational attainment, and whether its effect is beneficial or detrimental depends on gender. According to the second model, gay and bisexual men are more than twice as likely to have a bachelor's degree as compared to heterosexual men. This translates to a 16-percentage-point contrast in predicted probabilities. However, lesbian and bisexual women face an educational penalty. Even controlling for several variables, logistic regression results show that sexual minority women were less likely than even heterosexual men to have completed a bachelor's degree. Sexual minority women had the lowest predicted probability of the four gender and sexuality groupings to have a college degree by the end of wave 4 . Within gender, there is a difference of more than 9 percentage points between the predicted probabilities of sexual minority women having a bachelor's degree as compared to heterosexual women, and this difference is statistically significant if no adjustment is made to $p$ values. Of all gender and sexuality groups, sexual minority men actually had the highest predicted probability of having a college degree. This probability was not found to be statistically sig- 
nificantly different from that of heterosexual women, indicating that these two groups' patterns of educational attainment are similar. Likewise, significance tests of contrasts indicate that there is no statistically significant difference between the predicted probabilities of sexual minority women and heterosexual men having a college degree. This means that, for LGB people, sexual minority men's pattern of educational attainment more closely parallels that of heterosexual women, whereas sexual minority women's pattern more closely parallels that of heterosexual men.

Unadjusted tests of significance of this contrast support the third and fourth hypotheses: lesbian and bisexual women are less likely than their heterosexual female counterparts to have a bachelor's degree. This finding indicates that sexual identity has negative consequences for the educational attainment of sexual minority women. The female advantage in higher education, then, is conditional on sexual identity. LGB women do not enjoy the same female advantage in higher education that heterosexual women do. The Bonferroni tests of significance for the contrasts, though, complicate these findings. If this more stringent standard is used, the contrast between heterosexual women and LGB women's educational attainment levels is rendered insignificant. However, the Bonferroni tests of significance trade off Type I error for Type II error, making it more likely that the null hypothesis will be retained even if it is untrue. Because of the relatively small sample size of LGB respondents in Add Health, Bonferroni tests of significance may indicate that the relationship between gender, sexuality, and education is no greater than chance when, in fact, such a pattern does exist. Future research with larger samples of LGB respondents may be able to withstand the increased scrutiny of a Bonferroni test of significance. Additionally, as Add Health respondents' age and patterns of educational attainment stabilize, examination of future waves of data may be able to identify a pattern of educational attainment as contingent on sexuality and gender.

For those who work with college students, the results here indicate that more can be done to support sexual minority students' academic success - particularly for sexual minority women. For instance, academic tutoring services could collaborate with on-campus LGBT groups to communicate that such services are not only available but inclusive and aware of sexual minority students' needs. Career counseling may be another means of addressing the educational gaps between sexual minority men and women identified here. Although sexuality affects sexual minority women's career decisions (Boatwright et al. 1996), there may be little in the way of formal interventions for LGB college students. Paying more attention to the academic needs and career development concerns of sexual minority students may be a means of promoting academic success, for sexual minority women in particular, as well as for any sexual minority students who are facing academic difficulties. 
Institutions should also be more deliberate in collecting data on sexual minority student populations. As Sanlo (2004) points out, many American colleges and universities would be unable to determine how their LGBT students fare academically as compared to heterosexuals because they do not have a formal means of gathering information on their progress or their needs. By collecting data on sexual minority students, institutions will be better able to identify any gender and sexuality patterns in educational attainment and better design localized interventions to help promote all students' academic success.

These descriptive findings do much to untangle the relationship between gender, sexuality, and education. They also provide some direction for future research. Because I use self-identification as LGB at a later wave as my independent variable, endogeneity is a possible concern. I argue that timing of coming out is not of heightened concern in this work, whose goal is more descriptive than explanatory; regardless of when or how respondents disclosed their sexual identities, they still contribute to a pattern of educational attainment among sexual minorities. It is important to explore what mechanisms underpin these gender and sexuality differences in educational attainment, including timing of coming out, exposure to discrimination, or school culture. Future work should use other bodies of theory to propose hypotheses for the mechanisms that underpin these differences and explore them.

Cohort effects may be important, given Add Health's longitudinal design. The group of respondents in the Add Health data all fall between the ages of 25 and 35 at the time of wave 4 data collection, with over half of the respondents clustered within 1 year of age 30 . It is important to note that these data represent a particular cohort of people, most of whom finished high school right on the cusp of American society's relative transformation to a broader acceptance of sexual minorities (Broido 2004). The age of the respondents affects the generalizability of these data to all LGB persons; both older and younger LGB persons might experience disproportionate effects - and returns - on their educational attainment as a function of sexual identity. As data collection processes continue to emphasize including LGB populations, it is likely that more systematic data sources will collect information on respondents' sexual identity status (Black et al. 2000). These sources can be used to expand the work here past its limited focus on a particular cohort.

\section{Conclusion}

The analysis presented here indicates that there are differences in educational attainment between heterosexual and LGB respondents in the Add Health data. Gay and bisexual men's predicted probabilities of college completion are 
above those of both heterosexual men and sexual minority women. Sexual minority women, on the other hand, had the lowest predicted probability of having a bachelor's degree. Sexual minority men, then, experience an educational bonus in terms of bachelor's degree completion, but sexual minority women are educationally penalized. Sexual identity's effect on educational attainment is not monolithic. Rather, the interaction of gender and sexuality leads to differential educational attainment outcomes.

The finding that lesbian and bisexual women are less likely to obtain a bachelor's degree is all the more striking given the general female advantage in college completion and the LGB bonus identified in prior literature. The educational trajectories of sexual minority women should be studied to determine why they are disadvantaged as compared to their male counterparts. Those who wish to promote LGB student success should pay particular attention to the educational needs of sexual minority women, and future work could examine the mechanisms behind this gender- and sexuality-dependent differential in educational attainment. In the meantime, there are steps that educational institutions can take to address these educational disparities, such as promoting academic interventions for sexual minority students and collecting data on their graduation rates. Particularly because college completion has serious consequences, it is all the more important to explore why certain gender and sexuality groups may be advantaged - or disadvantaged - when it comes to obtaining a postsecondary degree.

\section{Notes}

Thank you to Liana Sayer, Claudia Buchmann, Cynthia Colen, and the anonymous reviewers for their helpful feedback on previous drafts. Prior iterations of this work were presented at the 2012 College Student Educators International (ACPA) Annual Convention, the 2012 Midwest Sociological Society (MSS) Annual Conference, and the North Central Sociological Association (NCSA) Annual Conference. This research uses data from Add Health, a program project directed by Kathleen Mullan Harris and designed by J. Richard Udry, Peter S. Bearman, and Kathleen Mullan Harris at the University of North Carolina at Chapel Hill, and funded by grant P01-HD31921 from the Eunice Kennedy Shriver National Institute of Child Health and Human Development, with cooperative funding from 23 other federal agencies and foundations. Special acknowledgment is due Ronald R. Rindfuss and Barbara Entwisle for assistance in the original design. Information on how to obtain the Add Health data files is available on the Add Health website (http://www.cpc.unc.edu/addhealth). No direct support was received from grant P01-HD31921 for this analysis.

1. This study does not specifically look at transgender persons. The data set used had fewer than five respondents who reported a transgender identity or a change in sex to warrant their inclusion in the analysis. Although transgender students are frequently 
overlooked in scholarly literature (Renn 2010), the omission here is made to avoid making generalizations to a group that frequently has different concerns than do LGB persons, as well as to avoid making generalizations that the data set cannot support.

2. Because the intersection of gender and sexuality is of empirical concern in this work, it is necessary to explain the language that will be used to distinguish between the four groups of interest. For instance, although this analysis examines the educational status of LGB people, separating these groups out by using terms such as "LGB men" is problematic, as the identity of lesbian is one that is infrequently claimed by sexual minority men (Zita 1992). Further, the use of terms such as "men" and "women" also presents difficulties; many sources use the terms interchangeably, conflating the gender and sex of their respondents (Valdes 1996). It is assumed in the data used here, for instance, that respondents who identify themselves as "male" would also identify themselves as men and present themselves as men, which may or may not be the case in reality. It is not my intention to further complicate the terrain of this debate here, though it is necessary to acknowledge its bearing on the analysis and its interpretation. Because of the conflation of sex and gender in the bulk of pertinent literature, I use the terminology originally employed by the respective authors cited when discussing others' works. For my own findings, I will use the terms "men" and "women" as nouns, and "male" and "female" as adjectives. For sexual identity, I will use "LGB" or "sexual minorities" as terms to talk about the population as a whole, but "sexual minority men/women," "gay and bisexual men," or "lesbian and bisexual women" will be used when I discuss the intersection of gender and sexuality. In its style guide, the American Psychological Association (2009) supports the use of these conventions in scholarly writing. Transgender or otherwise queer populations may be considered "sexual minorities," or they may use a multitude of different terms to label their gender or gender expression (Savin-Williams 2005). However, because there is no way for the data here to accurately determine whether respondents are transgender or otherwise non-gender conforming, the terms "sexual minority," "man," and "woman" used here will be employed as an intelligible shorthand representation of the data and arguments presented here. Their use is not meant to intentionally exclude.

3. See note 4; "gay males" is the terminology Barrett et al. (2002) used in their article.

4. Although Black et al. (2000) note that gay men are overwhelmingly concentrated in a few urban areas across the United States, lesbian women's residential patterns are far more diffuse. Therefore, a method that concentrates on urban respondents may be more likely to overestimate sexual minority women's educational attainment levels.

5. Chi-square tests of cross tabulations and simple OLS regressions (not shown) indicate the LGB population identified here did not differ substantially from heterosexual respondents in terms of parents' SES or urbanity. With regard to race, sexual minority men of color were overrepresented as compared to LGB white men. Thirtyseven of 857 men of color, or $4.32 \%$ of all men of color in the sample, identified as gay or bisexual. For white men, 33 of 1,366 respondents, or $2.45 \%$, identified as gay or bisexual (chi-square test is significant, $p<.05$ ). Given racial minority men's educational standing vis-à-vis white men's in general (e.g., McDaniel 2011), this overrepresentation makes the finding that the "LGB bonus" holds for men even more strik- 
ing. Therefore, there is little reason to believe that this subsample of sexual minorities differs substantially from the larger, nationally representative population of the Add Health survey.

6. Although the protected data would offer more statistical power, as the sample size is nearly three times that of what is presented here, I no longer have access to the full data set. Further, results using the protected data do not differ from those presented here, which use the publicly available Add Health data.

7. Although it would be ideal to separate out bisexual respondents from lesbian and gay respondents - particularly because of the differences between the concerns of bisexuals and those of lesbians and gay men (e.g., Phelan 2001; Weinberg et al. 1994), such a separation might compromise the statistical integrity of the model by splitting up LGB persons into subgroups too small to study. Future research with larger, purposeful sampling of LGB populations could be used to answer questions about differences between subgroups.

8. Much like transgender respondents, small sample size and the fact that asexuality is a distinct sexual identity with issues separate from those that heterosexuals and LGB persons face, coupled with the fact that asexuals comprised such a small percentage of respondents, led to the decision to exclude asexual respondents from this analysis (Boegart 2006; Savin-Williams 2005).

9. This percentage of LGB respondents matches the proportion of respondents who identify as sexual minorities when self-identification is used to operationalize sexual minority status (Laumann et al. 1994; Savin-Williams 2005). Kinsey et al.'s (1948) oftquoted statistic of $10 \%$ of the population being gay or lesbian stems from their use of engagement in same-sex sexual behavior as a means of operationalizing sexual minority status.

10. Add Health does ask respondents whether they are currently pursuing for-credit education. Given that the average age of respondents at wave 4 is 30 , it is possible that some of them have not yet completed their educational careers. I choose to use attainment of a bachelor's degree as a cutoff point in my analysis, as most Americans still complete their college degrees before the age of 30 (Jacobs and King 2002). Additionally, Add Health's question regarding current enrollment lumps together vocational/technical training with college, university, or community college enrollment, which is problematic given this work's interest in analyzing bachelor's degree completion. I also did not separate those enrolled in higher education as I ran multinomial logistic regression models including current pursuit of education as a competing outcome, and results were similar to those presented. Analysis of future waves of Add Health data may be able to determine whether there are any changes in the findings after more respondents have largely finished pursuing education.

11. Add Health's respondent data collection on parents refers to those individuals whom the respondents identify as their mother or father through a home census. This means that some parents may be stepparents, biological parents, or even guardians, depending on how the respondent identified them in their census.

12. An interaction effect between LGB sexual identity and self-esteem was tested in preliminary statistical models. However, the interaction variable was not statistically significant. Therefore, it is not included in the final models presented.

FEBRUARY 2015 
Sexual Identity, Gender, and Postsecondary Educational Attainment

13. On self-reports of academic performance, male respondents tend to overestimate their academic success more so than female respondents do (DiPrete and Buchmann 2012). The Add Health data have a companion survey, the Adolescent Health and Academic Achievement (AHAA) survey, which contains cumulative GPA data for respondents whose high schools were able and willing to provide transcripts. However, earlier models run with protected access to AHAA's measure of GPA, which has a lower potential for bias, meant an increased number of missing cases for the GPA variable. A disproportionate number of these otherwise-missing cases were LGB respondents (results not shown). Because of this, McNeely's (2005) operationalization for the GPA control variable is an acceptable proxy, even if access to Add Health's protected data were possible.

14. Presumably, the intersection of race and sexuality would lead to differential educational outcomes for LGB persons of color as compared to white LGB persons (Collins 2004). However, this split the LGB sample into even smaller subpopulations, which would have exacerbated issues related to statistical power. Qualitative research techniques or quantitative analysis of future data sets with larger numbers of LGB persons of color may be able to untangle any race/sexuality interactions that affect educational attainment.

15. The fact that a coefficient is not significant in one model, but becomes significant upon the addition of another variable, may indicate that statistical suppression is a concern (MacKinnon et al. 2000). Within-gender logistic regressions (results not shown) indicate that the variable for sexual minority status is quite robust, maintaining both statistical significance and direction for men and women. The results indicate this is a true interactive (moderating) relationship, wherein the interaction of gender and sexual identity leads to unique educational attainment outcomes: sexual minority women are less likely to earn a bachelor's degree than heterosexual women, whereas sexual minority men are more likely than heterosexual men to have completed college. Therefore, statistical suppression of the main effect to a degree that compromises the results presented here is not likely.

16. In logistic regression models with an interaction, interactive effects cannot be compared to one another directly as they can in linear models (Norton et al. 2004). Therefore, comparisons of magnitude of the effects gender and sexual identity have on bachelor's degree attainment will be examined after marginal effects are computed.

\section{References}

Allison, Paul. 2001. Missing Data. Thousand Oaks, CA: Sage.

American Psychological Association. 2009. Publication Manual of the American Psychological Association. 6th ed. Washington, DC: American Psychological Association.

Badgett, M. V. Lee. 2001. Money, Myths, and Change: The Economic Lives of Lesbians and Gay Men. Chicago: University of Chicago Press.

Barrett, Donald C., Lance M. Pollack, and Mary L. Tilden. 2002. "Teenage Sexual Orientation, Adult Openness, and Status Attainment in Gay Males." Sociological Perspectives 45 (2): 163-82. 
Bearman, Peter S., and James Moody. 2004. "Suicide and Friendships among American Adolescents." American Fournal of Public Health 94 (1): 89-95.

Black, Dan, Gary J. Gates, Seth G. Sanders, and Lowell Taylor. 2000. "Demographics of the Gay and Lesbian Population in the United States: Evidence from Available Systematic Data Sources." Demography 37 (2): 139-54.

Boatwright, Karyn J., Mary S. Gilbert, Linda Forrest, and Kay Ketzenberger. 1996. "Impact of Identity Development upon Career Trajectory: Listening to the Voices of Lesbian Women." Fournal of Vocational Behavior 48 (2): 210-28.

Bobbitt-Zeher, Donna. 2007. "The Gender Income Gap and the Role of Education." Sociology of Education 80 (1): 1-22.

Boegart, Anthony F. 2006. "Toward a Conceptual Understanding of Asexuality." Review of General Psychology 10 (3): 241-50.

Broido, Ellen M. 2004. "Understanding Diversity in Millennial Students." New Directions for Student Services 2004 (106): 73-85.

Brown, James Dean. 2008. "Statistics Corner: Questions and Answers about Language Testing Statistics: The Bonferroni Adjustment." Shiken: FALT Testing and Evaluation SIG Newesletter 12 (1): 23-28.

Buchmann, Claudia, and Thomas A. DiPrete. 2006. "The Growing Female Advantage in College Completion: The Role of Parental Resources and Academic Achievement." American Sociological Review 71 (4): 515-41.

Buchmann, Claudia, Thomas A. DiPrete, and Anne McDaniel. 2008. "Gender Inequalities in Higher Education." Annual Review of Sociology 2008 (34): 319-37.

Carpenter, Christopher S. 2009. "Sexual Orientation and Outcomes in College." Economics of Education Review 28 (6): 693-703.

Cass, Vivienne C. 1979. "Homosexual Identity Formation: A Theoretical Model." Fournal of Homosexuality 4 (3): 219-35.

Chapa, Jorge, and Belinda de la Rosa. 2004. "Latino Population Growth, Socioeconomic and Demographic Characteristics, and Implications for Educational Attainment." Education and Urban Society 36 (2): 130-49.

Chickering, Arthur W., and Linda Reisser. 1993. Education and Identity. 2nd ed. San Francisco: Jossey-Bass.

Collins, Patricia Hill. 2004. Black Sexual Politics: African-Americans, Gender, and the New Racism. New York: Routledge.

D’Augelli, Anthony R. 1993. "Preventing Mental Health Problems among Lesbian and Gay College Students." Fournal of Primary Prevention 13 (4): 245-61.

DiPrete, Thomas A., and Claudia Buchmann. 2012. The Rise of Women: The Growing Gender Gap and What It Means for American Schools. New York: Russell Sage Foundation.

Fine, Leigh. 2011. "Minimizing Heterosexism and Homophobia: Constructing Meaning of Out Campus LGB Life." Fournal of Homosexuality 58 (4): 521-46.

Goesling, Brian. 2007. "The Rising Significance of Education for Health?" Social Forces 85 (4): 1621-44.

Goldsmith, Pat Rubio. 2009. "Schools or Neighborhoods or Both? Race and Ethnic Segregation and Educational Attainment." Social Forces 87 (4): 1913-42.

Harris, Kathleen Mullins, Carolyn T. Halpern, Eric Whitsel, Jon Hussey, Joyce W. Tabor, Pamela Entzel, and J. Richard Udry. 2009. The National Longitudinal Study of Adolescent Health: Research Design. Retrieved May 25, 2011, from http://www.cpc.unc.edu/projects/addhealth/design.

Henrickson, Mark. 2008. "Deferring Identity and Social Role in Lesbian, Gay, and Bisexual New Zealanders." Social Work Education 27 (2): 169-81. 
Jacobs, Jerry A., and Rosalind Berkowitz King. 2002. "Age and College Completion: A Life-History Analysis of Women Aged 15-44." Sociology of Education 75 (3): $211-30$.

Kinsey, Alfred, Wardell B. Pomeroy, and Clyde E. Martin. 1948. Sexual Behavior in the Human Male. Bloomington: University of Indiana Press.

Kozol, Jonathan. 1991. Savage Inequalities: Children in America's Schools. New York: Crown.

Laumann, Edward O., John H. Gagnon, Robert T. Michael, and Stuart Michaels. 1994. The Social Organization of Sexuality: Sexual Practices in the United States. Chicago: University of Chicago Press.

Legewie, Joscha, and Thomas A. DiPrete. 2012. "School Context and the Gender Gap in Educational Achievement." American Sociological Review 77 (3): 463-85.

Longmore, Monica A., Wendy D. Manning, Peggy C. Giordano, and Jennifer L. Rudolph. 2004. "Self-Esteem, Depressive Symptoms, and Adolescents' Sexual Onset." Social Psychology Quarterly 67 (3): 279-95.

MacKinnon, David P., Jennifer L. Krull, and Chondra M. Lockwood. 2000. "Equivalence of the Mediation, Confounding and Suppression Effect." Prevention Science 1 (4): 173-81.

Masters, Ryan K., Robert A. Hummer, and Daniel A. Powers. 2012. "Educational Differences in Adult Mortality: A Cohort Perspective." American Sociological Reviewe 77 (4): $548-72$.

McDaniel, Anne, Thomas A. DiPrete, Claudia Buchmann, and Uri Shwed. 2011. "The Black Gender Gap in Educational Attainment: Historical Trends and Racial Comparisons." Demography 48 (3): 889-914.

McNeely, Clea. 2005. "Connection to School." In What Do Children Need to Flourish? Conceptualizing and Measuring Indicators of Positive Development, ed. Kristin Anderson Moore and Laura H. Lippman. New York: Springer.

Milligan, Kevin, Enrico Moretti, and Philip Oreopoulos. 2004. "Does Education Improve Citizenship? Evidence from the United States and the United Kingdom." Fournal of Public Economics 88 (9-10): 1667-95.

Morris, Edward W. 2008. "'Rednecks,' 'Rutters,' and 'Rithmetic: Social Class, Masculinity, and Schooling in a Rural Context." Gender and Society 22 (6): 728-51.

Norton, Edward C., Hua Wang, and Chunrong Ai. 2004. "Computing Interaction Effects and Standard Errors in Logit and Probit Models." STATA Fournal 4 (2): $154-67$.

Pampel, Fred C. 2000. Logistic Regression: A Primer. Thousand Oaks, CA: Sage.

Pascarella, Ernest T., and Patrick T. Terenzini. 2005. How College Affects Students. San Francisco: Jossey-Bass.

Perneger, Thomas V. 1998. "What's the Matter with Bonferroni Adjustments." British Medical Fournal 316 (7139): 1236-38.

Pharr, Suzanne. 1997. Homophobia: A Weapon of Sexism. Expanded ed. Berkeley, CA: Chardon.

Phelan, Shane. 2001. Sexual Strangers: Gays, Lesbians, and the Dilemmas of Citizenship. Philadelphia: Temple University Press.

Polikoff, Nancy. 2008. Beyond (Straight and Gay) Marriage: Valuing All Families under the Law. Boston: Beacon.

Renn, Kristen. 2010. "LGBT and Queer Research in Higher Education: The State and Status of the Field." Educational Researcher 39 (2): 132-41.

Rhoads, Robert A. 1995. "Learning from the Coming-Out Experiences of College Males." Journal of College Student Development 36 (1): 67-74. 
Roscigno, Vincent J., and Martha L. Crowley. 2001. "Rurality, Institutional Disadvantage, and Achievement/Attainment." Rural Sociology 66 (2): 268-92.

Rothblum, Esther D., Kimberly F. Balsam, Sondra E. Solomon, and Rhonda J. Factor. 2005. "Siblings and Sexual Orientation: Products of Alternative Families or the Ones Who Got Away?" Journal of GLBT Family Studies 1 (2): 71-87.

Ryan, James E. 2010. Five Miles Away, A World Apart: One City, Two Schools, and the Story of Educational Opportunity in America. New York: Oxford University Press.

Sanlo, Ronni. 2004. "Lesbian, Gay, and Bisexual College Students: Risk, Resiliency, and Retention." Fournal of College Student Retention 6 (1): 97-110.

Savin-Williams, Ritch G. 2005. The New Gay Teenager. Cambridge, MA: Harvard University Press.

Sewell, William H., A. O. Haller, and Alejandro Portes. 1969. "The Educational and Early Occupational Attainment Process." American Sociological Review 34 (1): 82-92.

Taylor, Verta, Katrina Kimport, Nella Van Dyke, and Ellen Ann Andersen. 2009. "Same-Sex Weddings and Gay Activism." American Sociological Review 74 (6): 86590.

US Census Bureau. 2012. "Educational Attainment by Selected Characteristic." http://www.census.gov/compendia/statab/2012/tables/12s0231.xls.

Valdes, Francisco. 1996. "Unpacking Hetero-Patriarchy: Tracing the Conflation of Sex, Gender and Sexual Orientation to Its Origins." Yale Fournal of Law and the Humanities 8 (1): 161-211.

Weinberg, Martin S., Colin J. Williams, and Douglas W. Pryor. 1994. Dual Attraction: Understanding Bisexuality. New York: Oxford University Press.

Zita, Jacquelyn N. 1992. "Male Lesbians and the Postmodernist Body." Hypatia 7 (4): 106-27. 